\section{Colloquium at the Dublin Institute for Advanced Studies}

IN July a colloquium was held at the Dublin Institute for Advanced Studies at which the following lecturers each gave a short course of lectures : Prof. C. Møller (Copenhagen), Prof. J. L. Synge (Pitts. burgh), Dr. C. F. Powell (Bristol). Prof. Møller discussed the centre of gravity in relativistic quantum mechanies, explaining how this notion can be defined in a quantized field theory and how it is related to the angular momentum and the 'trembling motion'. Prof. Synge dealt with more mathematical subjects of boundary problems and multiply connected spaces. For the non-mathematician, Dr. Powell's lectures on meson tracks in the photographic emulsion were most interesting. His and Occhialini's discovery of the existence of two kinds of mesons with different masses of which the heavier decays spontaneously into the lighter kind was widely discussed. It seemed most probable that the ordinary cosmic ray meson is identical with the lighter kind, and that at least the heavier meson is the "meson of the nuclear forces" predicted by Yukawa, and is strongly coupled with nuclei. Examples of meson emission in nuclear disintegrations which were shown in the lectures also prove that the general ideas of the meson theory are correct. It is as yet an open question whether also the light meson is strongly coupled with nuclei or not. This depends on further experiments, in particular on the question whether the mesons ejected in nuclear disintegrations are all heavy or also partly light mesons. It depends also on whether the fact that ordinary negative mesons are not captured in light elements (delayed coincidence experiments) can be understood theoretically or not. If it should turn out that the light meson is also a nuclear force meson, then the form of meson theory proposed by Møller and Rosenfeld and modified by Schwinger (vector and pseudoscalar mesons with different masses) is most likely correct.

\section{Rainfall Records of Australia}

A serious gap in the official rainfall records for Australia for the period 1939-45 would not have come as a surprise, but with the receipt recently of the 1945 issue of the official "Rain Map of Australia", it is elear that there is no such gap, but only some delay in printing. The disturbance of national life caused by the War was not allowed to affect the continuity of the 1,300 selected observing stations which are used when the official monthly and annual maps are prepared, maps which are said in the opening paragraph of the notes that accompany them to give a very fair representation of the rainfall distribution over Australia. That a number of the less. important private observing stations had to be dis. continued seems only too probable, especially in northern regions from which the population was evacuated and to which the strategy of 'scorched earth' was applied. Very brief study of the notes that accompany the rainfall maps for this last year of the War is sufficient to reveal the unstable character of the Australian climate.

In Great Britain snowstorms, floods, extremes of temperature and drought, such as those of the early part of 1947, can be fairly described as departures from 'normal' or 'average' conditions. In Australia such descriptions are almost without meaning. The 1945 notes show what happens when this fact is not taken into account. For example, the following appears under the heading "New South Wales": "In nearly every respect the year 1945 is possible of classification as a normal year. . . Rainfall was well distributed during the months of January, February, May, June, July and August, but the very heavy rains that were registered in coastal divisions during April and June caused highly destructive floods on the Northern Rivers, and enormous damage was done.... In the Richmond Basin particularly the destruction was regarded as being greater than at any time in the history of the river." So the tale goes on. Towards the end of the year, lack of rain and short bursts of heat interfered with dairying in the metropolitan zone of that State, and made a measure of rationing necessary. Grass fires were frequent. Temperatures were "not far removed from normal", yet caused eleven deaths at Broken Hill in a 7-day spell of "high readings" at inland stations. Frosts were widespread and severe during the winter and snowfall on the Alps heavier than usual. It is scarcely necessary to quote from the descriptions of weather in the regions where the weather was not described as so nearly normal ; but there is a characteristic note for Western Australia that possibly answers the natural question as to why anyone wants to live in a country with such a climate. It appears that the wheat crop there amounted to $20,500,000$ bushels, in spite of excessive winter rains and insufficient "finishing rains" in the south.

\section{Film-Strip of the Principles of Bridges}

Messrs. StripSuides, 93 Cheyneys Avenue, Canons Park, Edgware, Middlesex, have submitted a copy of StripSlide No. 47/1, "The Principles of Bridges", edited by G. Ghey, of the Royal Naval College, Dartmouth. This StripSlide consists of 35 frames. The foreword to the text which accompanies it states that "it is designed for one or two lectures whose twofold object is : (i) to give a mechanics class which has been taught the principle of moments some applications of this principle in the different types of bridges; (ii) to enable people better to appreciate a bridge when they see one and to realize how the different types are related to each other. At this level the treatment is necessarily sketchy. Though the author believes that he is telling the truth, he is well aware that it is far from being the whole truth; but if thereby the audience is encouraged to think and to ask questions the cause of education will have been furthered." The film deals picturesquely, and on the whole clearly, with shearing force, bending moment, plain beams, reinforced concrete spans, cantilever bridges and suspension bridges. Examples are shown, and the theoretical treatment, although necessarily superficial, is as adequate as can be expected in a short strip. Besides fulfilling the purpose for which it is designed, it might well be used to arouse the interest of a class in preparation for a more serious course.

\section{Archæological Research in South Africa}

RESEARCH workers are usually so busy piling brick on brick on the edifice of human knowledge that there is never time for them to stand back and survey what has been built and how it has been done. The "Loom of Prehistory" (South African Arch. Soc., Handbook Series No. 2. Pp. 152), by A. J. H. Goodwin, seeks to correct this, and attempts "some analysis of the interweaving elements of time, culture, man and area in the light of past research and publication". Students of South African pre- 
history will find this book of 151 pages very useful on three counts. The story of prehistoric research in the area is given, with mentions of some of the people who were particularly concerned; the situation as it is known to-day is summarized and attractively set out; a good bibliography is appended. Dr. van Riet Lowe has written two papers (South African J. Sci., 42; 1946), one concerned with a special bipolar technique of flaking found in the coastal Smithfield industries, and tho other suggests that there is evidence to maintain that Stellenbosch man possessed certain artistic qualities. Some chipped stone objects have been found which seem to show a feeling for symmetry. In the same journal Dr. Malan describes the distribution and chronology of the Modderpoort culture. It is suggested that the term proto-Magosian would well describe the industries belonging to this culture.

\section{Technical State Scholarships}

THe Minister of Education has now issued the regulations (Grant Regulations No. $5 A$ ) which will govern the award of technical State scholarships. These scholarships will be tenable at universitios, university colleges and institutions of further education which prepare students for degrees or equivalent qualifications. In order to be eligible for an award under theso regulations, a candidate must $(a)$ be a British subject ordinarily resident in England or Wales, $(b)$ have completed a course leading to an ordinary national certificate or diploma or a course accepted by the Minister as of equivalent standard, and be recommended for such an award by the principal of an establishment for further education, (c) have been in full-time or part-time attendance at such an establishment for a period of not less than two years immediately preceding August 1 of the year in which the award is made, and $(d)$ be under the age of twenty on July 31 in that year. Candidates will not be eligible for these awards if they are assisted by the Minister under any other body of regulations, or if they are recognized students in training colleges in respect of which the Minister pays grant.

\section{Smithsonian Institution Publications}

A Classified Lrst of Smithsonian Publications Available for Distribution, December 1, 1946, compiled by $H$. Munroe, has now been issued as Publication 3858. Applicants for the papers in this list, which are distributed gratis, except where price is given, are requested to state the grounds for their requests, as the Institution is only able to supply papers as an aid to research or studies in which applicants are especially interested. Papers listed in the series of Contributions to Knowledge and Miscellaneous Collections are not public documents, and the limited editions are distributed without charge to public libraries, educational establishments and learned societies in the United Statos and abroad, and are supplied to other institutions and to individuals at the prices indicated. The Smithsonian Report volumes and the papers reprinted from them are distributed gratuitously by the Institution to libraries and individuals throughout the world. Many of these volumes of which the Smithsonian edition is exhausted can be purchased from the Superintendent of Documents, Government Printing Office, Washington. The Institution maintains mailing lists of libraries and educational establishments but no general mailing list of individuals.
Veterinary Educational Trust : Canine Committee

A Canine Committee has been formed in connexion with the Veterinary Educational Trust, and Mr. F. W. Gentle will be its chairman with Mr. H. S. Lloyd as his deputy. Dr. W. R. Wooldridge, scientific director of the Trust, announced at the inaugural meeting of this Committee that the canine research station, now in the process of formation at Newmarket, will cost $£ 25,000$ to complete, and that $£ 20,000$ a year would be needed for conducting its activities. The Greyhound Racing Association had promised the Trust $£ 10,000$ a year for seven years for the work of the Newmarket station.

\section{New Scientific Journals}

Two new scientific journals, both published by the Elsevier Publishing Co., Inc., New York and Amsterdam, are Analytica Chimica Acta, an international journal dealing with all branches of analytical chemistry, edited by Paul E. Wenger (Geneva), published monthly, subscription 9.50 dollars per annum; and Biochimica et Biophysica A cta, an international journal of biochemistry and biophysics, with an editorial board, at an annual subscription of 9.00 dollars. We have received copies of the first numbers of both journals, which are of high standard. Papers are in English, French and German.

\section{British Herpetological Society}

Aт the inaugural meeting held on July 11, the following were elected as the first officers of the British Herpetological Society : President, Dr. Malcolm A. Smith, British Museum (Natural History); Hon. Secretary and Treasurer, Mr. Alfred Leutscher, British Museum (Natural History) and 5 St. Margaret's Court, London, E.12 ; Hon. Editor, Dr. Angus Bellairs, Department of Anatomy, London Hospital ; Members of Committee, Dr. Helen Spurway, Depart. ment of Zoology, University College, London, and Mr. H. W. Parker, British Museum (Natural History). It is proposed to hold meetings quarterly, if possible, in London; with an increase in membership from the provinces, outside meetings would also be considered.

\section{Announcements}

THE fifteenth Thomas Young Oration of the Physical Society will be delivered by Prof. F. Zernicke, of the University of Groningen; he will speak on "Diffraction and Optical Image Formation", and the lecture will be delivered at the Imperial College of Science and Technology, London, on September 24 at 5.10 p.m.

THE seventh series of post-graduate lectures of the London Section of the Oil and Colour Chemists' Association will be delivered by Sir Lawrence Bragg, who will give "A Review of Recent Advances in X-Ray Analysis". The lectures will be given at the Royal Institution, Albemarle Street, London, W.1, on Octobor 2, 9 and 16 at 6.30 p.m. Admission will be by ticket only, obtainable from H. C. Worsdall, c/o Messrs. Plastanol, Ltd., Crabtree Manorway, Belvedere, Kent.

Dr. LUIGI GorINI states that the communication entitled "Biochemistry of Escherichia coli and the Production of Penicillinase" (Nature, Sept. 6, p. 332) requires the following corrections: par. 3, last line, for "towards the acid or alkaline side" read "towards the alkaline side" ; par. 4, line 13, for "included" read "excluded"; par. 6, line 6, for "in this way" read "on the other hand". 